past history of parental loss, neglect, or cruelty. The escapist alcohol addicts, in contrast, seem often from their own accounts to have been pampered, over-indulged children.

Three personality categories were defined, and after clinical assessment on referral each patient was assigned to the one considered most appropriate:

1. Impunitive patients were those thought to be hedonists, carefree and uninhibited people, not inclined to blame themselves for failures or misdemeanours. They were low in hostility, and certainly did not turn aggressiveness upon themselves.

2. Moderately self-punitive patients were those who expressed remorse for the harm they caused other people, who were self-critical and discussed their failings, and were assessed as low in self-esteem.

3. Grossly self-punitive patients were conspicuous for selfreproach and self-disgust. Some referred to themselves as rubbish, devils, monsters, or outcasts. Women placed in this category sometimes said they were prostitutes or evil. These harshly self-critical patients often roused much concern and attention in other patients and in treatment staff as a result of their castigation of themselves.

TABLE V.-Relation Between Conscience-structure and Outcome After

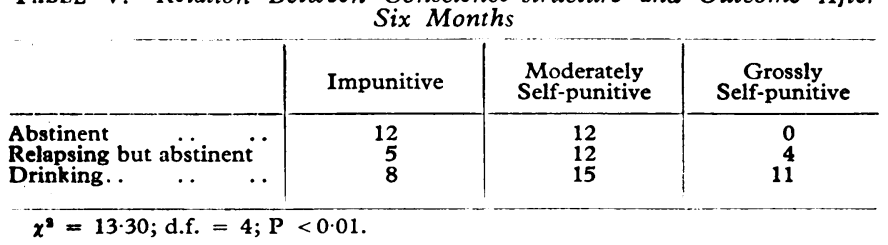

Table $\mathrm{V}$ shows that the alcoholics who did best in treatment (as judged by their drinking status six months after referral) were the moderately self-critical patients. The next most favourable outcome occurred in the impunitive patients (hedonists). Those who responded least well to treatment, not one of them achieving abstinence, were the patients rated as grossly self-critical.

\section{Summary}

Over half the alcohol addicts treated in a specialized clinic were found to be abstinent after six months and also after 18 months. Many of these abstinent patients had episodes of drinking, showing that for them outpatient treatment after the initial hospitalization had been necessary. Although few needed readmission, the number requiring outpatient support increased with the length of the follow-up period.
Outcome was studied in relation to psychiatric diagnosis, pattern of drinking, and conscience-structure. Patients with mild personality disorders responded best in treatment ; patients with psychoneurosis and moderate personality disorder fared equally well, not supporting the belief sometimes advanced that psychoneurotic symptoms in addition to addiction make for particularly good prognosis. Psychopathic addicts did least well.

The regular, restrained form of addiction, not catered for by Alcoholics Anonymous, was the drinking pattern of a substantial proportion of patients, although the more florid loss-ofcontrol form of addiction was the commoner.

Of greater prognostic significance than either the associated psychiatric disorder or the addictive pattern was the patient's conscience-structure. Addicts with moderately self-critical traits did best in treatment ; next most favourable was a conscience of escapist type; none of the grossly self-punitive patients succeeded in becoming abstinent.

\section{REFERENCES}

Bonhoeffer, K. (1901). Die Akuten Geisteskrankheiten der Gewohnheitstrinker. Fischer, Jena.

Davies, D. L., Shepherd, M., and Myers, E. (1956). Quart. F. Stud. Alcohol, 17, 485.

Gerard, D. L., and Saenger, G. (1959). Ibid., 20, 620.

Glatt, M. M. (1959). Lancet, 2, 397.

Gliedman, L. H. (1958). In Problems of Addiction and Habituation, edited by P. H. Hoch and J. Zubin. Grune and Stratton, New York.

Jellinek, E. M. (1960). The Disease Concept of Alcoholism. Hillhouse Press, New Haven.

Kessel, N., and Walton, H. (1965). Alcoholism. Penguin Books, Harmondsworth, Middlesex.

McCarthy, R. G. (1946). Quart. F. Stud. Alcohol, 6, 500.

McCulloch, W. (1965). "Deliberate Self-poisoning or Self-injury." M.Sc. Thesis, University of Edinburgh.

Ministry of Health (1962). Memorandum, H.M. (62) 43. Ministry of Health, London.

Morrison, S. L. (1964). Hlth Bull. (Edinb.), 22, 12.

Parr, D. (1957). Brit. F. Addict., 54, 25.

Ritson, E. B. (1966). M.D. Thesis, submitted to University of Edinburgh.

Scottish Home and Health Department (1966). Alcoholics. Report on Treatment and Rehabilitation. H.M.S.O., Edinburgh.

Straus, R., and Bacon, S. D. (1951). Quart. F. Stud. Alcohol, 12, 231.

Walton, H. (1961). Amer. F. Psychiat., 118, 410.

Wolff, S., and Holland, L. (1964). Quart. f. Stud. Alcohol, 25, 108.

World Health Organization (1951). Techn. Rep. Ser., No. 42. Geneva

\title{
Erythema Multiforme, Drugs, and Ulcerative Colitis
}

\author{
A. J. CAMERON,* M.B., M.R.C.P. ; J. H. BARON,* D.M., M.R.C.P. ; B. L. PRIESTLEY,* M.B., M.R.C.P., D.C.H.
}

Brit. med. F., 1966, 2, 1174-1178

Erythema multiforme occasionally occurs in patients with ulcerative colitis, and may present in the severe exudative form known as the Stevens-Johnson syndrome. In this paper we describe four such cases. Previous reports of this association are reviewed and also cases in which the Stevens-Johnson syndrome followed the use of drugs for conditions other than colitis. We suggest that erythema multiforme occurring in a patient with ulcerative colitis is usually a complication not of the disease itself but of its treatment with a sulphonamide.

\footnotetext{
- From the Middlesex and Central Middlesex Hospitals, London.
}

A 42-year-old schoolmistress was admitted to hospital on 2 November 1953 with a nine-weeks history of bloody diarrhoea (5 to 10 motions daily), colicky lower abdominal pain, anorexia, and vomiting. Her previous health had been good apart from asthma during adolescence. She was thin, her temperature was $100.4^{\circ} \mathrm{F}$. $\left(38^{\circ} \mathrm{C}\right.$.), and lower abdominal tenderness was noted. Sigmoidoscopy showed a granular proctitis. Haemoglobin was $10.2 \mathrm{~g} . / 100$ ml., W.B.C. 7,600/c.mm., and E.S.R. $50 \mathrm{~mm}$. per hour (Westergren). No pathogens were isolated on stool culture. Changes compatible with mild ulcerative colitis involving the descending and sigmoid colon were seen on barium enema. 
It is not known whether she had taken any drugs before her admission. In hospital phthalylsulphathiazole, $8 \mathrm{~g}$. daily, and phenobarbitone and amylobarbitone sodium were given from 2 November. Diarrhoea and fever persisted until the terminal stages of her illness. On 9 November, in addition to these drugs, treatment was begun with penicillin, 500,000 units twice daily, streptomycin, $1 \mathrm{~g}$. daily, both given intramuscularly, and sulphadimidine, $1 \mathrm{~g}$. four times daily, by mouth. On 11 November, one and threequarter hours after the start of a blood transfusion, she developed an erythematous rash on the forearms and oedema of the face. The oedema had disappeared by the next morning. By 16 November a new papular rash had appeared on the forearms. This rash progressed so that eventually there were large areas of erythema and bullae on the face, trunk, arms (including palms), and legs. There were ulcers on the lips, tongue, and buccal mucosa, bilateral purulent conjunctivitis, and a yellow vaginal discharge. Fluid from a skin bulla was sterile on culture. Sulphonamides were stopped for 24 hours after the onset of the papular rash, but then were started again. From 24 November A.C.T.H., 20 units four times daily, was given intramuscularly. However, her condition continued to deteriorate, and she died on 29 November.

Necropsy showed, in addition to the skin lesions, bronchopneumonia, and the changes of ulcerative colitis, mainly left-sided. The colonic mucosa was dark red and polypoid, with superficial ulceration, and the regional lymph nodes were enlarged.

\section{Case 2}

In June 1955 an 18-year-old mechanic developed scattered erythematous macules and vesicles on his face, chest, and limbs without mucous membrane or constitutional involvement. These lesions were regarded as typical of erythema multiforme. He was treated with chlortetracycline and local applications, and the rash resolved after 10 days.

On 22 May 1957, at the age of 20, he was admitted to hospital with a one-day history of abdominal discomfort, with loose stools containing blood and mucus. He was afebrile, there was tenderness in both iliac fossae, and sigmoidoscopy showed an acute granular proctitis. The haemoglobin, white blood count, and plasma proteins were normal, and no pathogens were found in the stools. $\mathrm{He}$ was given phenobarbitone and ferrous gluconate. His symptoms persisted with anorexia and malaise, and he became febrile $\left(99^{\circ} \mathrm{F}\right.$., $37.2^{\circ} \mathrm{C}$.). On 6 June sulphadimidine, $1.5 \mathrm{~g}$. four times a day, was started. On 11 June he was ill with coryza, sore throat, and vomiting. By 12 June he had a productive cough, dyspnoea, cyanosis, and a temperature of $105.4^{\circ} \mathrm{F}$. $\left(40.8^{\circ} \mathrm{C}\right.$.). The conjunctivae were injected, the lips were ulcerated, and the body was covered with erythematous macules, which became vesicular and then bullous. During the next two days these bullae became confluent over almost the whole body except the scalp, and in addition there were mucopurulent lesions of the conjunctiva, lips, gums, mouth, pharynx, scrotum, glans penis, prepuce, and urethra. $\mathrm{He}$ was treated with local and systemic corticosteroids and antibiotics, intravenous fluids, and blood transfusions. Over the next six months the skin and genital lesions wept, then dried and peeled, the mouth healed, and the eye lesions cleared apart from a residual keratitis. However, his severe colitis failed to remit, and he died suddenly on 26 December 1957.

Post-mortem examination showed a massive pulmonary embolus that had resulted from popliteal-vein thrombosis. The entire colon was congested and thickened, and showed loss of mucosal pattern. Microscopically there was a mucosal and submucosal inflammatory reaction with irregular dilated glands containing pus.

\section{Case 3}

A 40-year-old clerk was admitted to hospital on 21 February 1960. Two weeks earlier, while recovering from an influenza-like illness, he had developed diarrhoea, passing 8 to 10 motions containing blood and mucus daily. Before admission he had received a sulphonamide (the records do not specify which drug was used), and also a broad-spectrum antibiotic and a mixture to control diarrhoea. In 1951 he had been treated with para-aminosalicylic acid for pulmonary tuberculosis.
In hospital he was given chloramphenicol and propantheline bromide, but did not improve. Sigmoidoscopy on 11 March showed a hyperaemic, oedematous, and friable rectal mucosa thought to be typical of proctocolitis. On $16 \mathrm{March}$ lesions appeared on the skin and in the mouth, he became febrile, and his general condition deteriorated. He had by now lost 2 stones $(12.7 \mathrm{~kg}$.) in weight since the start of his illness.

He was transferred to another hospital on 26 March. At this stage he was passing two to four motions daily. His temperature was $103^{\circ} \mathrm{F}$. ( $39.4^{\circ} \mathrm{C}$.). He had a rash, mostly maculopapular with occasional vesicles, on the arms and thighs, some of the lesions being typical erythema iris. There were many grey ulcers on the palate and pharynx, and a single vesicle on the glans penis. The conjunctivae were clear. Abdominal tenderness, maximal in the left iliac fossa, was noted, but there were no other abnormal signs. Haemoglobin was 14.1 g./100 ml., W.B.C. 11,500/c.mm., E.S.R. $23 \mathrm{~mm}$. per hour. Plasma $\mathrm{Na}+$ was $122 \mathrm{mEq} / 1$., $\mathrm{K}+3.6 \mathrm{mEq} / \mathrm{l}$, $\mathrm{Cl}-95 \mathrm{mEq} / \mathrm{l}$., and plasma protein $6.5 \mathrm{~g}$. with $2.8 \mathrm{~g}$. of albumin per $100 \mathrm{ml}$. No pathogenic organisms were cultured from a mouth swab. Chest $x$-ray examination showed healed calcified tuberculous lesions only.

He was treated with intravenous fluids, A.C.T.H. in an initial dose of 120 units intramuscularly daily, rectal hydrocortisone, topical hydrocortisone to the skin lesions, and oral tetracycline. Streptomycin and isoniazid cover was also given because of the previous tuberculosis. He improved and his temperature fell to normal after two days. Sigmoidoscopy on 5 April showed two shallow ulcers just inside the anal sphincter. The rectal mucosa was abnormal, being oedematous and with no visible vascular pattern, but there was no bleeding. By 11 April the skin lesions had cleared completely, but then a large painful anal ulcer overlying a perianal abscess appeared. He again became febrile. Two bottles of blood were transfused, and the abscess was incised and drained. Biopsy of the ulcer edge showed a non-specific inflammatory reaction with many plasma cells. The anal lesion healed over the next few weeks, during which time his bowel action returned to normal (one a day). A barium enema on 20 May showed changes typical of ulcerative colitis involving the whole colon. He was well when he left hospital on 9 June 1960, and had remained well when last seen in April 1961.

\section{Case 4}

A 50-year-old housewife noticed, in August 1959, an itchy red "pimply" rash on both forearms, and also had diarrhoea, symptoms which lasted only a few days. Three months later diarrhoea recurred with colicky abdominal pain, and after a few days she was admitted to hospital. An emergency laparotomy showed a hyperaemic oedematous sigmoid colon, and a proximal colon distended with hard faeces. The appendix was removed. Sigmoidoscopy revealed the changes of ulcerative colitis. Phthalylsulphathiazole and succinylsulphathiazole were given postoperatively, and she was later treated with oral prednisone, the maximum dose being $30 \mathrm{mg}$. daily. Smaller doses of oral prednisone were given for the next two years, and she was subsequently treated with prednisolone-21-phosphate enemas alone. Intermittent mild diarrhoea (two to four motions daily) persisted, with some rectal bleeding.

On 31 August 1963 she was given sulphasalazine (Salazopyrin), $1 \mathrm{~g}$. three times daily. Eighteen days later she felt unwell and feverish ; the next day a rash appeared. The sulphasalazine was then stopped, and she was admitted to hospital on 22 September. She was ill, with a temperature of $102^{\circ} \mathrm{F} .\left(38.9^{\circ} \mathrm{C}\right.$.), and there was a rash involving the face, trunk, and limbs, most marked in deeply sunburnt areas. There were many papules 0.5 to $1 \mathrm{~cm}$. in size, a number of which later became bullous. Large bullae appeared on palms and soles. There were bilateral purulent conjunctivitis, oedema of the face, vesicles and ulcers on the tongue and buccal mucosa, and later also perianal and vulval ulceration. There were no other abnormal signs. The haemoglobin level was $12 \mathrm{~g} . / 100 \mathrm{ml}$., W.B.C. 5,800, with a normal differential, and the E.S.R. (Westergren) $100 \mathrm{~mm}$./hour. No pathogens were isolated from the mouth ulcers. She was treated with oral prednisone (in a maximum dose of $80 \mathrm{mg}$. daily), oral tetracycline, and local hydrocortisone and antibiotics for the eyes. The rash slowly resolved, and after five weeks the skin lesions had almost completely healed. During her stay in hospital there was no diarrhoea, and indeed she was passing one formed motion only once every few days. Before her discharge 
home on 31 October sigmoidoscopy showed no evidence of activity of the colitis. Three months after leaving hospital she remained well.

\section{Stevens-Johnson Syndrome}

In 1922 Stevens and Johnson described an illness with involvement of the skin and mucous membranes occurring in two children. They considered that this was a previously unrecognized entity. However, the view is now generally held (Wheeler, 1963 ; Brit. med. F., 1964) that the disease these authors described was in fact a severe form of erythema multiforme, a condition first recognized by von Hebra in 1860. The term "Stevens-Johnson syndrome" is commonly used to describe an illness in which the cutaneous lesions of erythema multiforme are accompanied by bullae, ulceration of the conjunctivae, mouth, and genitalia, with systemic upset and fever. Other names that have been given to the same condition include ectodermosis erosiva pluriorificialis and erythema multiforme exudativum major. There is no clear distinction between the Stevens-Johnson syndrome and mild erythema multiforme, as cases of intermediate severity occur with varying degrees of mucosal involvement.

\section{Aetiology of Erythema Multiforme}

No single causal agent can account for all cases of this disorder. Standard textbooks of dermatology list many conditions with which it may be associated. These include a wide variety of apparently unrelated infections and non-specific inflammatory diseases. Erythema multiforme may occur after drugs, especially sulphonamides. In many cases, however, no adequate cause is discovered. This applies also to the major form of the disease. Ashby and Lazar (1951) reviewed 77 previously reported cases of the Stevens-Johnson syndrome, and added four of their own. In seven of these 81 cases a sulphonamide had been given previously. In two cases the sulphonamide had

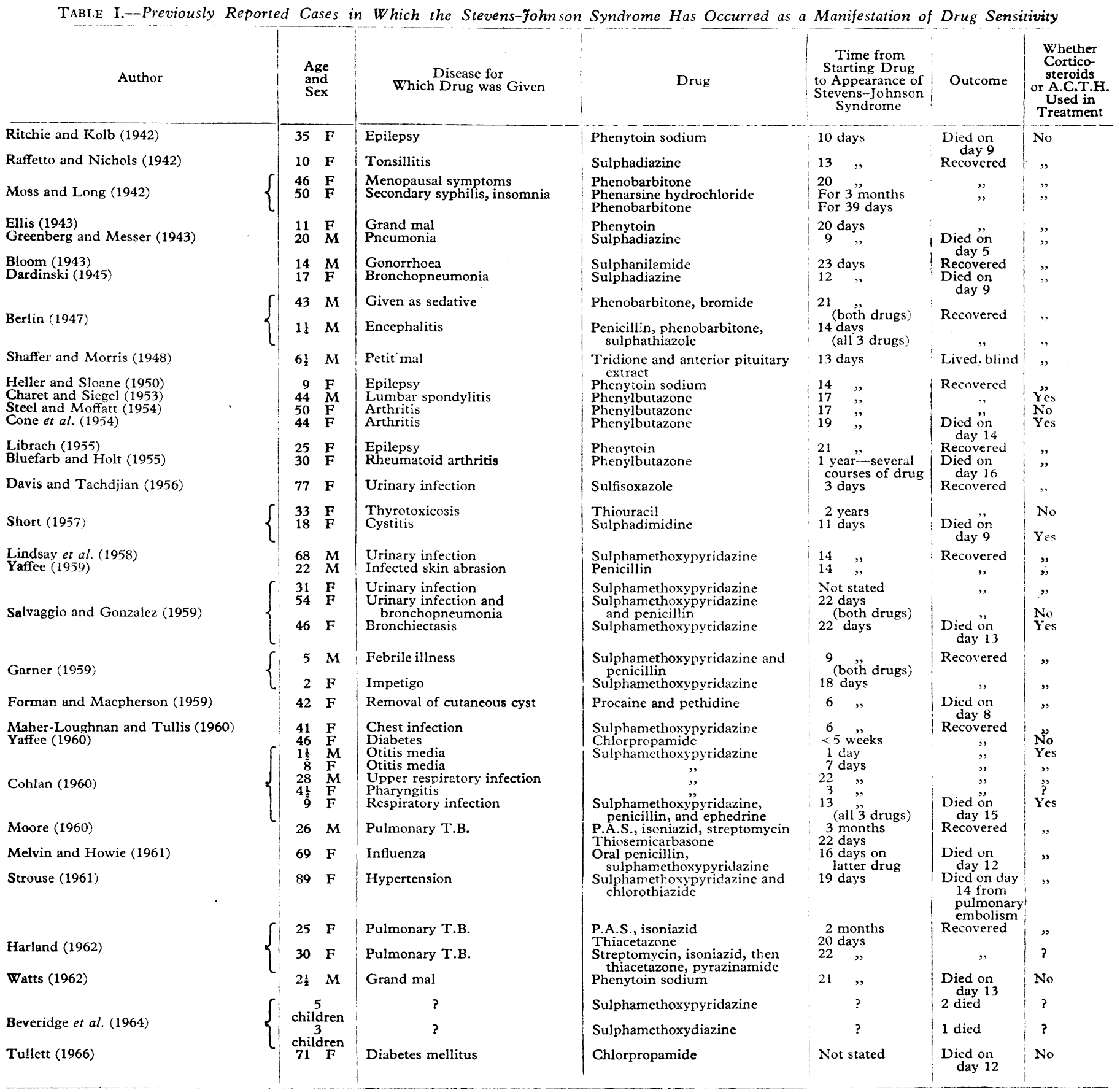


again been given after recovery from the initial attack, and had caused relapse.

\section{Association of Erythema Multiforme with Colitis : Previously Reported Cases}

Sloan, Bargen, and Gage (1950), analysing the case records of 2,000 patients with chronic ulcerative colitis seen at the Mayo Clinic between 1918 and 1937, noted "important cutaneous lesions" in 45 cases; two of these had erythema multiforme.

Crawford and Luikart (1949) reported a case of erythema multiforme in which the large bowel was involved by an ulcerating process. Their patient was a 26 -year-old woman who first had a transient conjunctivitis accompanied by a mouth lesion. Nine months later these symptoms recurred, but in addition there was a maculopapular rash and diarrhoea. The second episode lasted for a week. Three months afterwards a severe illness began, the initial symptom being diarrhoea followed after four days by the typical lesions of the Stevens-Johnson syndrome, the skin, conjunctivae, mouth, and vulva being involved. On proctoscopy there were a few ulcers 0.5 to $1 \mathrm{~cm}$. in the rectum. Barium enema showed mucosal swelling with ulceration involving the entire colon proximal to the mid-sigmoid, the process stopping abruptly at the ileocaecal valve. The attack was treated with penicillin and later sulphadiazine, but these drugs were given only after the rash had appeared. The patient recovered symptomatically, though a further barium enema still showed an abnormal colonic mucosa. Crawford and Luikart considered that the ulcerating process in the colon was an extension of the mucocutaneous lesions of erythema multiforme; but it seems equally possible that their patient had idiopathic proctocolitis ("ulcerative colitis"), appearing simultaneously with erythema multiforme.

Hightower, Broders, Haines, McKenney, and Sommer (1958) state that they have seen erythema multiforme in chronic ulcerative colitis, but do not give further details.

Rankin, Goulston, Boden, and Morrow (1960) noted erythema multiforme as a complication in two of their cases of fulminant relapse of chronic ulcerative colitis. One, a 20-yearold man, died seven days after operation for his colitis. The other, a man aged 47, recovered. Details of drug therapy before the onset of the rash are not given.

Kelley (1962) described three cases of erythema multiforme in patients with ulcerative colitis. In each case the latter involved the entire colon, as shown on barium enema. None had mouth or genital ulcers and one only had unilateral conjunctivitis, so the clinical picture was not as severe as in the Stevens-Johnson syndrome. In the first patient, a 54-year-old woman, the rash began on the third day of treatment of a relapse of long-standing colitis with sulphathalidine $6 \mathrm{~g}$. daily. The rash, with conjunctivitis, recurred with a relapse of her colitis nine months later, and the possibility that this was due to drug sensitivity cannot be excluded on the history given.
The second patient was a boy of 10 who had been treated for his colitis with sulphathalidine, chloramphenicol, and phenobarbitone, and developed erythema multiforme involving the skin only. The third patient was a woman of 33 , in whom the rash appeared during a severe first attack of colitis after 10 days' treatment with sulphasalazine, $8 \mathrm{~g}$. daily, and phenobarbitone.

Edwards and Truelove (1964), in their survey of 624 patients with ulcerative colitis in the Oxfordshire area, found three patients with erythema multiforme.

Kelley (1962) concluded: "It would seem that the most likely underlying cause of erythema multiforme in these patients was their ulcerative colitis." However, patients suffering from ulcerative colitis .usually have been given drugs, and these may themselves cause erythema multiforme as a sensitivity phenomenon. We have tried to assess the importance of this factor.

\section{Erythema Multiforme as a Manifestation of Drug Hypersensitivity}

As noted earlier, our own four cases had the fully developed Stevens-Johnson type of erythema multiforme. We have therefore reviewed all the cases described in the English language in which the Stevens-Johnson syndrome has occurred following the use of drugs (Table I). Cases where a drug appeared to have been given during the period of prodromal symptoms that often precedes the rash by a day or two have been excluded. We have found records of 50 cases ; 29 were female and 13 male (Beveridge et al. (1964) do not state the sex of their cases). Ages of these patients ranged from 15 months to 89 years. Many different primary illnesses had led to drug treatment being given. Twenty-nine cases followed the use of sulphonamide, and in 19 of these the drug was sulphamethoxypyridazine. Phenytoin sodium had been given in five cases, and phenylbutazone in four.

Table I also shows the time interval from first taking the drug until the onset of the Stevens-Johnson syndrome. Sometimes the drug had been stopped for a number of days before this complication occurred. It is remarkable that in almost all these cases the Stevens-Johnson syndrome appeared within 23 days of the start of a course of drug therapy. The exceptions were one patient who had taken phenarsine hydrochloride (Clorarsen) for three months and phenobarbitone for 39 days ; another had taken thiouracil for two years; and a third had had several courses of phenylbutazone during the previous year.

\section{Conclusion}

Details of our own cases are summarized in Table II for comparison with Table I. All four patients had received a sulphonamide preparation. In Case 3 the interval between

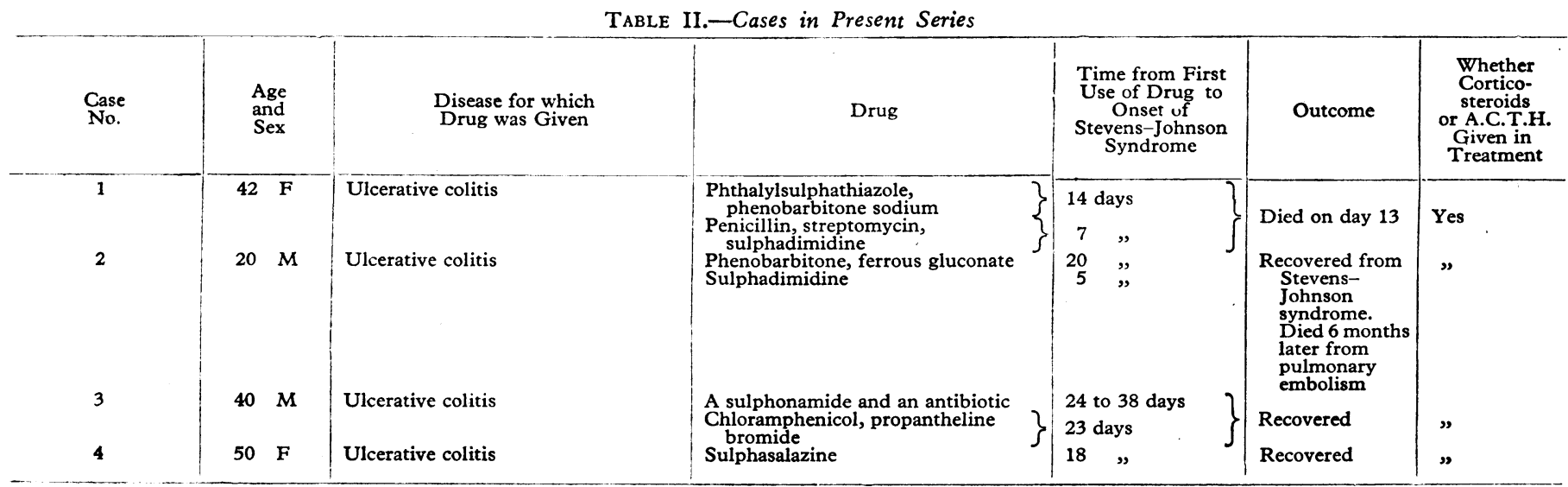


starting the drug and the appearance of the Stevens-Johnson syndrome was a few days longer than in previously reported cases due to drug sensitivity. In Case 4 our patient was given sulphasalazine because other measures had failed to arrest her chronic mild colitis. The appearance of the skin and mucosal lesions shortly afterwards seems to have been related to the change of medication, as no exacerbation of the colitis occurred around that time. There appear to be no previous reports of the Stevens-Johnson syndrome complicating sulphasalazine therapy, though in one of the cases described by Kelley (1962) the patient developed the simple cutaneous variety of erythema multiforme while taking this drug. Sulphasalazine has a sulphonamide-like structure; Svartz (1942) states that the blood of patients taking sulphasalazine always contains free sulphapyridine.

It seems unlikely that the Stevens-Johnson syndrome involves the gastrointestinal tract directly other than at the oral and anal regions. Necropsies have been performed in a number of cases where the syndrome followed the use of drugs, and in most of these there was no abnormality in the intestine. However, Ritchie and Kolb (1942) noted haemorrhagic gastritis and enteritis. Dardinski (1945) observed numerous petechial haemorrhages throughout the gastrointestinal tract, and Bluefarb and Holt (1955) found that the gastrointestinal tract was congested with ecchymoses in the rectum and sigmoid colon. The post-mortem findings in these three cases were not those of ulcerative colitis, but may well have been non-specific terminal changes.

In conclusion, with the single exception of the case of Crawford and Luikart (1949), the association between erythema multiforme and ulcerative colitis could, in all patients known to us, be explained by the erythema multiforme being due to a reaction to drugs (usually sulphonamides) given for the colitis.

One final clinical point: of 54 patients with the StevensJohnson syndrome listed in Tables I and II, 17 died and one was permanently blinded. The deaths were almost always due to the Stevens-Johnson syndrome rather than to the underlying disease for which the drugs responsible had been given. The prognosis has not greatly improved with the advent of corticosteroids ; 9 of 26 patients treated with A.C.T.H. or corticosteroid died.

We would advise that if a patient with ulcerative colitis develops the Stevens-Johnson syndrome any drug possibly responsible should be stopped immediately.

\section{Summary}

Four cases of severe erythema multiforme (Stevens-Johnson syndrome) occurring in the course of ulcerative colitis are described. All had been treated with a sulphonamide before the onset of this complication.

Previously reported cases of the association of erythema multiforme with colitis are reviewed, as are cases in which severe erythema multiforme followed the use of drugs given for conditions other than colitis.
It is probable that in most instances erythema multiforme as a complication of ulcerative colitis is due to drug hypersensitivity.

We wish to thank Dr. G. D. Hadley, Dr. F. Avery Jones, and Dr. I. M. Librach for permission to publish reports on patients under their care.

\section{REFERENCES}

Ashby, D. W., and Lazar, T. (1951). Lancet, 1, 1091. Berlin, C. (1947). Acta med. orient. (Tel-Aviv), 6, 101.

Beveridge, J., Harris, M., Wise, G., and Stevens, L. (1964). Lancet, 2, 593.

Bloom, D. (1943). N.Y. St. F. Med., 43, 1499.

Bluefarb, S. M., and Holt, L. (1955). Illinois med. f., 107, 37.

Brit. med. 7., 1964, 2, 1410.

Charet, R., and Siegel, I. (1953). F. Amer. med. Ass., 151, 556.

Cohlan, S. Q. (1960). Ibid., 173, 799.

Cone, R. B., Hannigan, C. A., and Teicher, R. (1954). Arch. Derm. Syph. (Chic.), 69, 674.

Crawford, G. M., and Luikart, R. H. (1949). f. Amer. med. Ass., 140 780.

Dardinski, V. J. (1945). Amer. F. clin. Path., 15, 28.

Davis, J. B., and Tachdjian, M. (1956). F. Amer. med. Ass., 161, 228.

Edwards, F. C., and Truelove, S. C. (1964). Gut, 5, 1.

Ellis, F. A. (1943). Sth. med. F. (Bgham, Ala.), 36, 575.

Forman, W. L., and Macpherson, C. R. (1959). Ohio St. med. J., 55, 1110 .

Garner, R. C. (1959). New Engl. f. Med., 261, 1173.

Greenberg, S. I., and Messer, A. L. (1943). f. Amer. med. Ass., 122, 944.

Harland, R. D. (1962). Tubercle (Lond.), 43, 189.

Hebra, F. (1860). In R. Virchow's Handbuch der Speciellen Pathologie und Therapie, 3, 198. Erlanger, Stuttgart.

Heller, G., and Sloane, M. (1950). Pediatrics, 5, 836.

Hightower, N. C., Broders, A. C., Haines, R. D., McKenney, J. F., and Sommer, A. W. (1958). Amer. F. dig. Dis., 3, 861.

Kelley, M. L. (1962). Ibid., 7, 255.

Librach, I. M. (1955). Postgrad. med. F., 31, 570.

Lindsay, D. G., Prlina, I., Bischoff, A. J., and Becker, S. W. (1958). Arch. Derm., 78, 299.

Maher-Loughnan, G. P., and Tullis, D. C. (1960). Lancet, 1, 202.

Melvin, K. E. W., and Howie, R. N. (1961). Brit. med. F., 2, 869.

Moore, W. (1960). Tubercle (Lond.), 41, 448. Moss, R. E., and Long, W. E. (1942). Arch. Derm. Syph. (Chic.), 46,

Raffetto, J. F., and Nichols, S. (1942). 7. Pediat., 20, 753.

Rankin, J. G., Goulston, S. J. M., Boden, R. W., and Morrow, A. W. (1960). Quart. F. Med., 29, 375.

Ritchie, E. B., and Kolb, W. (1942). Arch. Derm. Syph. (Chic.), 46, 856.

Salvaggio, J., and Gonzalez, F. (1959). Ann. intern. Med., 51, 60.

Shaffer, B., and Morris, P. (1948). Pediatrics, 2, 30.

Short, I. A. (1957). Lancet, 1, 290.

Sloan, W. P., Bargen, J. A., and Gage, R. P. (1950). Gastroenterology, 16, 25 .

Steel, S. J., and Moffatt, J. L. (1954). Brit. med. F., 1, 795.

Stevens, A. M., and Johnson, F. C. (1922). Amer. f. Dis. Child., 24, 526.

Strouse, C. D. (1961). New Engl. f. Med., 264, 39.

Svartz, N. (1942). Acta med. scand., 110, 577.

Tullett, G. L. (1966). Brit. med. F., 1, 148.

Watts, J. C. (1962). Pediatrics, 30, 592.

Wheeler, C. E. (1963). In Cecil-Loeb's Textbook of Medicine, edited by P. B. Beeson and others, 11 th ed., p. 500 . Saunders, London.

Yaffee, H. S. (1959). Arch. Derm., 79, 591.

(1960). Ibid., 82, 636. 